\title{
Colour Symbolism in a Nigerian Church: The Case of Prophet/Evangelist Abiodun Oladele of the Overcomers' Evangelical Ministries International (Ori-Oke Asegun)
}

\author{
Oluwasegun Peter ALUKO, Ph.D., Adenike Oluwabukola IREYOMI \\ Department of Religious Studies, Obafemi Awolowo University, Ile-Ife, Nigeria
}

\begin{abstract}
Colour holds a specific significance in the life of people and plays a certain role even in the environment. Most people place emphasis on the colour they make use of in an everyday affair. On the religious scene, colour is also an important element in the day-to-day activities that churches place great emphasis on the kind of colour being used. One of the many churches is the Overcomers' Evangelical Ministries International with its leader being an ardent user of a specific colour. Thus, this paper examines the colour symbolism in white and the charismatic leader's preference for the white colour. It also assess the impact of the usage of the white colour on the charismatic leader and the church at large. The approach being employed for this paper is the descriptive phenomenological approach.
\end{abstract}

\section{INTRODUCTION}

$\mathrm{I}$ $n$ most church buildings in Nigeria, one of the most eyecatching symbols is colour. This is because colour is the fundamental building block of visual symbols (Yu, 2014). Symbols, be it objects, images, sounds, actions, gestures, utterances, and almost any other medium have a specific meaning they stand for (Eller, 2007, p.55). The meaning a particular colour gives to one person or a particular Christian denomination may be different from another based on interpretation and perception. And, just as a particular colour may have different meaning to different people, so also a particular colour may be more preferred to another colour. Thus, it could be rightly said that colours hold significance for people around the world; they hold meaning in religion and various cultures (Colour Symbolism and Culture, n.d.).

Many Christian churches in Nigeria have one colour or the other that gives them a specific identity. Once people come across the colour(s), it is very likely they are able to predict rightly the kind of church that makes use of such colour(s). This is because colour differentiates one church from the church. The case is not different from that of the Overcomer's Evangelical Church International, whose leader and founder place much emphasis on a particular colour. The use ofthe colour white is very conspicuous in the church that one could say it has now becomea major defining identity of the leader of the church in particular and the church in general. Just as Hutchings (1997, p.55) was able to note rightly that colour is not a quality of an object, but a perception and as such, can symbolise anything we want it to symbolise, the church's charismatic leader, Prophet/Evangelist Abiodun Oladele places much emphasis on the colour white. Apparently, there are other colours being used by the church but the colour white stands out in its distinctiveness and significance. This paper examines the colour symbolism in white, the charismatic leader's preference for the white colour and the impact of the usage of the white colour on the charismatic leader and the church at large. The approach being employed for this paper is the descriptive phenomenological approach.

\section{BACKGROUND INFORMATION ON PROPHET/EVANGELIST ABIODUN OLADELE}

Prophet/Evangelist Abiodun Oladele is a man of great height, dark in complexion and with clear sight. Born on $25^{\text {th }}$ December, 1966, the name Abiodun is as a result of his birth that coincided with one of the so many festive periods in Nigeria, Christmas Day. Though, he was given birth to in IleIfe, he hails from Ogbomoso South in Oyo State. When talking about the circumstances that surrounded his birth, he said: "On the day my mother was to put to bed, that was on the Christmas Day, she heard a voice that said 'a great child would be given birth to in this house', and immediately, she fell into labour and delivered me" (Abiodun Oladele, personal communication, September 29, 2014). While growing up, he was unable to further his education to the higher institution; he later got enrolled as a village health worker through the help of the Local Government. This made him to be a "trained village physician". He got married to OdunolaOladele on $6^{\text {th }}$ December, 1994, and they as couple are blessed with three children.

\section{Call and Acceptance of Call}

The calling of Abiodun Oladele into ministry can be likened to the one of Prophet Muhammad in the cave of Hira that has to do with an angel of God coming to him and giving him the mandate of ministry. However, the one of Prophet Abiodun Oladele has to do with him being in the house and the angel of God coming down to him with a great light, sitting down on the bed with him. He claimed it was not a dream and neither was it a revelation. He said: 
The angel of God came to me, not as a dream or as a revelation. He sat down with me and we had a chat for almost two hours from $3 \mathrm{am}-5 \mathrm{am}$. As the angel was about to leave, he asked me to ask God for three things. I asked for the power of God to begin to manifest in my life (personal communication, September 29, 2014).

This singular vision of his is the event that brought about his call into the ministry.Notwithstanding, as a village health worker, after the encounter with the angel of God, he began to feel the power of God over his life. Instead of healing people with the orthodox medicine, he began to pray on water for patients to use purposively for the healing of whatsoever sickness that may be battling with them. For instance, he claimed to have prayed on water and this water healed a person that was suffering from paralysis of the leg. This person was actually brought to him for healing via the orthodox medicine, since he was a village health worker. It was further claimed that the person was healed three days after using the water Oladele prayed on. To Oladele, this event was supposed to act as the beginning of his ministry but he declined to start the ministry. With high income from being a health worker, Oladele was unwilling to leave his work for the ministry. While his wife was earning 730,000 naira (per year) as a teacher, he was earning an average rate of 5,000 per day. Nevertheless, it was not until after seven years (from the healing of the man with the paralysis) that his ministry started.

Oladele faced series of problems and confrontations that showed he would die if he does not accept the call of God. He heard a voice, whichsaid, "either you serve me or you die" (Abiodun Oladele, personal communication, September 29, 2014). Even with the voice he heard, he still did not heed to the will of God. However, he fell sick after a while which brought a turnaround to his life. The sickness happens to be more of an inner sickness than one that is quite visible to people. It was an inner sickness because he was looking good outside but sick within, that he was even donating blood to people. He suffered this illness for the seven years he refused to yield to the call to ministry. However, when he was nearing death, he met a man of God (name not known) who told him that he has about three months for him to repent or die. On hearing the word from his sickness, he packed his baggage out of his workplace without telling people, and left for the ministry to which God has called him. The day he was able to yield himself to the call of God was the day he got his healing from the supposed inner sickness.

On doing this, God told him to enter the bush and pray for thirteen days. While in the bush, on a particular rock in the said period, God gave him sixty-three revelations that have to do with his ministry. Coming down from the bush, he met a man named Enoch Gbadegesin. This man happens to be one of the nurses at the hospital where his blood was tested during the period of his "inner sickness". More so, out of the sixtythree revelations he received, one was for this man. This man invited Oladeleto a church known as Christ Way Church, which was the church he was attending. The invitation was for a three-day programme in which Oladele ministered with miracles and healing.

\section{Founding of Overcomers Evangelical Ministry International} (OEMI)

After the set man, Abiodun Oladele had yielded to the call of God, he continued to minister at Christ Way Church. Nevertheless, when he wanted to start his own ministry, he started at a place called "Mercy Land" beside Jolly in Ede road, Ile-Ife. It was claimed God had told him to move to a bush in Modomo Layout in Ajebandele, Ile-Ife, which he heeded. He said the Lord told him that many people would come looking for him in the bush (Abiodun Oladele, personal communication, September 29, 2014).

From May 1 to May 7, 2003, he was in this bush (which is the present site of the headquarters of the ministry) praying and fasting(incidentally, the church has now turned this into a symbolic annual seven-day prayers and fasting known as Covenant Days of Blessing). Oladele was in this said bush for three months. While in this bush, he encountered many situations that called for the exercising of the power of God on his life. Notable among the situations is the one of the devil coming to him, complaining that his prayers on the mountains have been affecting his kingdom. This event made him to be sick but God revived him. More so, he was able to overcome all the problems that he faced as concerning the establishment of the church. With the event in the bush, Oladele was able to start the founding of the Overcomers Evangelical Ministry International, popularly known as the Overcomers' Chapel (Ori-Oke Asegun).

\section{Colour Symbolism}

As noted earlier, symbols are things, be it objects, images, sounds, actions, gestures, utterances, and almost any other medium - that 'mean' something, that 'have a meaning' (Eller, 2007). But in a broader sense, Kierman (1991, p.26) defines a symbol as a unit for storing, carrying and transmitting meaning, several layers of which may be lodged in a single symbol. He went further by saying that:

The natural empirical things of everyday experience are drawn upon as symbols because, clearly, the carrier of meaning must be of an order different from meaning itself. And the more common and familiar are natural things in human experience, the more suited are they to their role of purveying meaning. Among this wide range of potential symbols are colour and its varieties (Kiernan, 1991).

From the above, it could be deduced that colour is the symbol that bears a particular meaning or the other, depending on the perspective in which it is being approached. According to Dzulkifli and Mustafar (2013), colour is the most important visual experience of human beings. It plays an important role in life, affects human perception, shifting meanings of symbols, emphasizes or suppresses communication of pictograms, logos, brands, acts on emotional perception, affects mood (Vik, Viková \& Kania, 2014). On the other 
hand, symbolism is described as the use of multiple symbols (in this case, colour) representing differentiated terms in a system that conveys meaning ( $\mathrm{Li}, 2015)$. Thus, it could be rightly said that, colour symbolism is the use of colour to represent traditional, cultural, or religious ideas, concepts, or feelings or to evoke physical reactions (Bear, n.d.), depending on different perspectives.

According to Zammitto (2005), there is a theoretical distinction of three backgrounds for meanings attached to colour and they are: an innate, a personal, and a cultural background. On the innate perspective that draws majorly from anthropological and behavioural research, there is the internal categorisation of colours that brings information and triggers arousal whenever human sees colours. The second background comes from each of human personal experiences in life. The third deals with cultural background that human beings are born and bred, which are full of meaning and this meaning is learnt through socialisation processes. This third background is in consonance with Yu (2014) who opines that, interpretations of colour may differ and the symbolism varies with the cultural environment. It will not be out of context to say that many people would favour the cultural aspect of meanings being ascribed to colour, as there is no person that is isolated from the culture and way of life of the environment he/she finds himself/herself. This is because colour meanings and symbolisms throughout the world depend on the culture and ethnicity of the people (Kwakye-Opong, 2014).

Adding to the spiritual dimension of colour symbolism, Antubam (1963, pp.78-80) while describing colour symbolism among Ghana people opines that, colour does not depend on scientific analysis but rather on philosophies embedded in their abstract and spiritual values. This means that the meaning given to colour goes farther than mere explanation using science, as the people depend more on spiritual explanation. This is true also of the Yoruba as colours were used as symbols for gods and goddesses in representative form for the deities (Oluwole, Ahmad \&Dilshan, 2013). According to Ajibade and Obongha (2012), colours may have physical, social and psychological symbolism. The physical symbolism tends to deal with what could be seen physically like in the instance of traffic lights, where red means stop, yellow means caution and green, means go. On the other hand, social symbolism deals with colours that represent the society or used by a particular community or country in terms of national colours like Nigeria's green-white-green or the American's red, white and blue) perceived as 'patriotic' when used as flags or in branding. Also, the psychological symbolism talks about colours from the psychic perspective where colours represent a particular situation and time. For instance, red and green symbolising the Christmas, emotions being symbolised by colours, where red is strong and symbolises power, blue is seen as conservative and brighter colours such as yellow and orange represent emotional warmth. But just as Ajibade and Obongha (2012) citing
Brusatin had warned, it is difficult to organise colour into a rigid system of symbols.

\section{The Symbolism of Colour White}

The colour white has different meaning to different people. Prophet/Evangelist Abiodun Oladele shows preference for the colour white. The colour white has come to be synonymous with Prophet/Evangelist Abiodun Oladele as he is always clad in white clothes. Nevertheless, it is not to say that he does not have preference for other colours like the use of the blue which he said was his primary school house colour (for sport).

If there is any other name that should be given to the charismatic leader, it should be called 'Baba White' (White Man), coming from his preference for the white colour. He is always clothed in white attire, that is, white top and short, white socks, white belt, and white shoes; uses white microphone when he wants to minister, and sits on white seat. Everything to him is white. However, when he was asked about the usage of anything that has to do with white, he said:

God told me in a dream when I asked why the devil was able to inflict me with illness, that there was a sin in me which was the sin of disobedience. I was told to always appear in white but I refused thinking that people will say one or two things in a bad way about my usage of white apparel. However, God told me not to mind anything people say, that I should start putting on white, and that is the genesis of white wearing (AbiodunOladele, personal communication, September 29, 2014).

Breidenbach (1976), while commenting on the general meanings of the traditional colour triad, said: "Earlier ethnographers all indicate that white is taken as the colour of the sacred" (see also Antubam, I963). The colour white seems to be sacred to Prophet/Evangelist AbiodunOladele as it was when he started making use of the white colour that those evil things no longer inflict any illness on him.In this instance, it could be rightly said that Oladele's attachment of meaning to colour white has a connection with his personal experience and especially one that has to do with a spiritual interpretation.

To Oladele, the colour white symbolises purity, sanctification and holiness. In the same light, he claimed the colour white is what everyone will put on when they get to heaven. Nevertheless, the use of only white colour does not stop him from allowing the building of his church to be painted with both white and blue as he noted that the colour blue symbolises mercy. More so, he accepted the use of blue in addition to white from the fact that he was in Blue House during his elementary studies. Notwithstanding, he believes the colour blue symbolises mercy.

However, one question being asked is the fact that if God has said he should always be in white, did God also instruct thathe should always sit on white chairs, use white microphone etc? More so, why wouldnot he make his body white or his car tires all white? Nevertheless, if the ancient Greeks wore white 
to bed in order to ensure good dreams (Smith, n.d.)why would not Prophet/Evangelist Abiodun Oladele put on white anytime, any day?

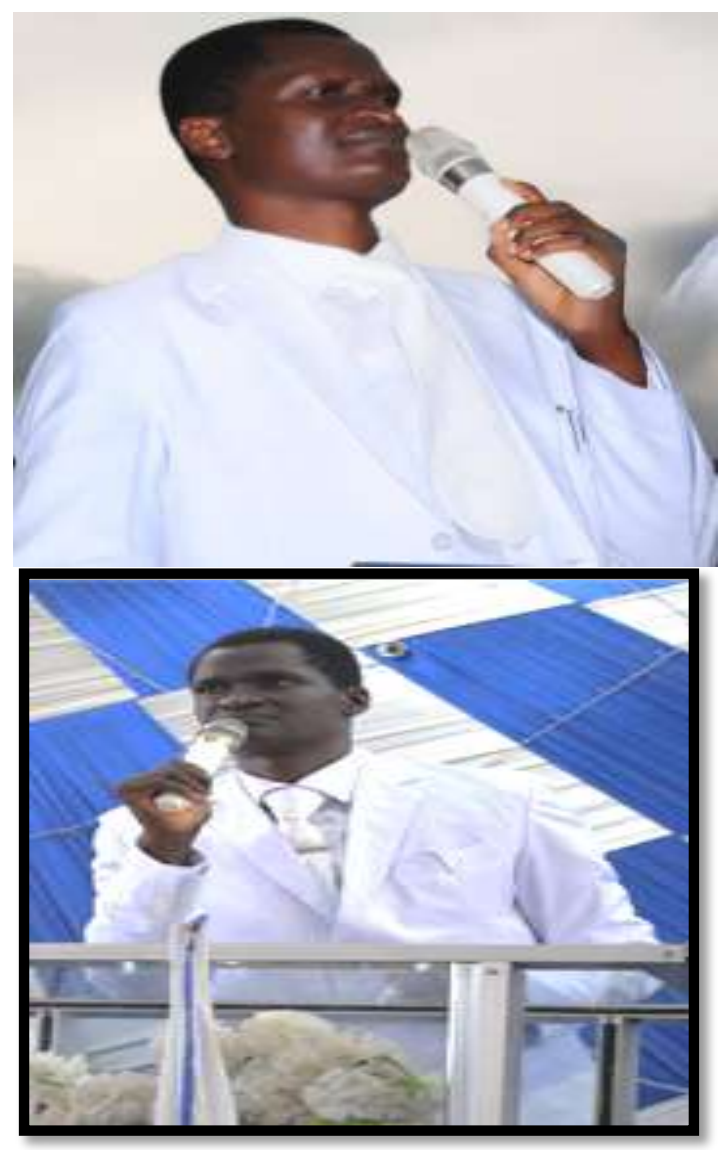

Figure 1: Prophet/Evangelist Abiodun Oladele during his ministration

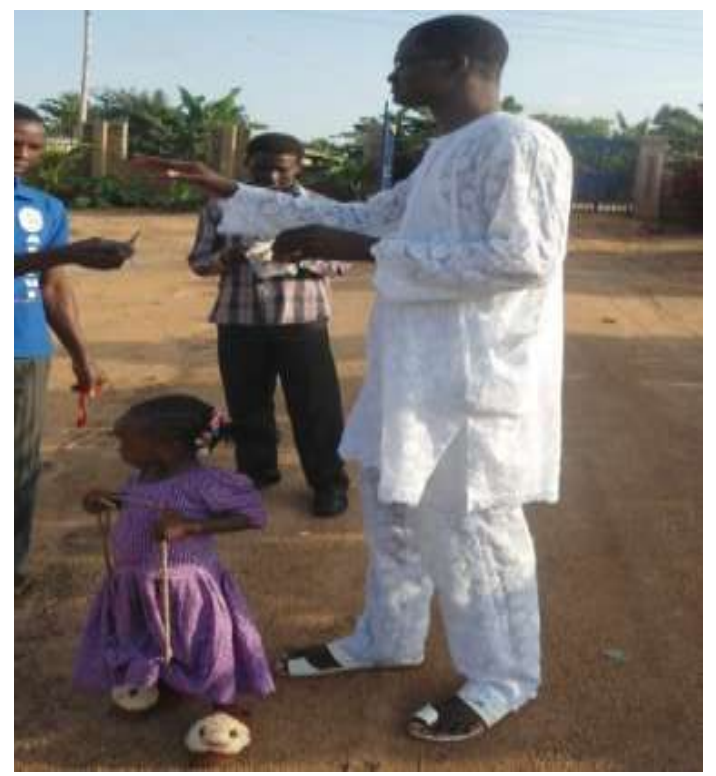

Figure 2: Prophet/Evangelist AbiodunOladele on a casual day besides the ministry days
The meaning given to colour is shaped by the forces of history, plan, and accident, and has a bearing on the way we think about colour, the way we react to it (Parikh, 2011). The colour white according to Mollon (2006, p.305) is known as "the mother of all unique hues". In Christianity, it represents the pure conscience, clear of stain because it is the purest of all hues (Yu, 2014). White projects purity, cleanliness, and neutrality. Doctors don white coats, Western brides traditionally wear white gowns, and a white picket fence denotes a safe and happy home (Smith, n.d.). With these, it not surprising why Oladele is being clad in white.

\section{IMPACT OF THE WHITE COLOUR}

The use of the white colour has had so many impacts on the life of Prophet/Evangelist AbiodunOladele and his ministry. Prominent among these various impacts is the fact that the use of white has helped him to overcome evil forces that were tormenting him at the beginning of his ministry. He believed God was the one who asked him to be making use of the colour white and not just his own making. In another vein, the colour white has created an identity for him, as people now know him for the use of white colour in all ramifications. It was after his call by God into the ministry and his acclaimed victory over evil spirits that brought about the use of white colour.

With the sacredness of the white colour, Oladele's church members are now imbibing the habit of making use of white colour, not minding the genesis of the use of the white colour by the leader. The degree to how the white colour has really affected the members cannot be known alongside the level of purity, sanctification, and holiness claimed to be it symbolism by the leader. One of the members said: "Nothing stops me from putting on white because I am under a covenant and it makes me to be identified with the man of God, his anointing and covenant" (George Adewoyin, personal communication, October 25, 2014).

\section{CONCLUSION}

Like many other colours that have one significance or the other on people, the colour white play so many roles in shaping the thoughts and actions of not just Prophet/Evangelist AbiodunOladele but even his church members. Having claimed the use of the colour white to have helped in more or less shielding him from the attack of the devil, it has also brought about peace of mind to him. More so, the use of white has affected the psyche of some of the church members that can make them to go all the way in order to emulate this charismatic leader. It can be rightly said that personal preferences, memories or associations affect colour perception (Vik, Viková \& Kania, 2014).

\section{REFERENCES}

[1] Ajibade, B., \&Obongha, S. E. (2012). Conscious or arbitrary: Colour and symbolism in carnival Calabar. Arts and Design Studies. 4, 12-23.

[2] Antubam, K. (1963). Ghana's heritage of culture. Koehler \&Amelang. 
[3] Bear, J. H. (N.d.). Colour symbolism. Retrieved from http://desktoppub.about.com/cs/color/a/symbolism.htm Accessed $15 / 11 / 2014$

[4] Breidenbach, P. S. (1976). Colour symbolism and ideology in a Ghanaian healing movement. Africa: Journal of the International African Institute. 46(2), 137-145.

[5] Colour symbolism and culture. (N.d.). Retrieved from http://www.incredibleart.org/lessons/middle/color2.htm Accessed $15 / 11 / 2014$.

[6] Dzulkifli, M., \&Mustafar, M. (2013). The influence of colour on memory performance: A review. The Malaysian Journal of Medical Sciences. 20(2), 3.

[7] Eller, J. D. (2007). Introducing anthropology of religion: Culture to the ultimate. Routledge.

[8] Hutchings, J. (1997). Folklore and symbolism of green. Folklore. $108,55-63$.

[9] Kiernan, J. P. (1991). Wear 'N' tear and repair: The colour coding of mystical mending in Zulu Zionist churches. Africa: Journal of the International African Institute. 61(1), 26-39.

[10] Kwakye-Opong, R. (2014). Clothing and colour symbolisms in the Homowo festival: A means to sociocultural development. Research on Humanities and Social Sciences. 4(13), 112-125.

[11] Li, N. (2015). Symbolic meanings of red and black. Theory and Practice in Language Studies. 5(6), 1313-1317. http://dx.doi.org/10.17507/tpls.0506.27
[12] Mollon, J. (2006). Monge: The Verriest lecture, Lyon, July 2005. Visual Neuroscience. 23, 297-309. http://doi.org/10.1017/S0952523806233479

[13] Oluwole, F. C., Ahmad, M. H. H., \&Dilshan, R. O. (2013). Colour utilization among the Yorubas of southwest Nigeria: An empirical analysis. Journal of Basic and Applied Scientific Research. 3(5), 78-82.

[14] Parikh, K. (2011). Colour symbolism: Emotional values of colour. Indian Journal of Applied Research. 3(1): 65-66. http://doi.org/10.15373/2249555X/JAN2013/26

[15] Smith, K. (N.d). Colour: Meaning, symbolism, and psychology. Retrieved from http://sensationalcolor.hubpages.com/hub/colorexpert-2 Assessed $15 / 11 / 2014$

[16] Vik, M., Viková, M., \&Kania, E. (2014). Semantic symbolism of colours. Conference paper: 20th International Conference STRUTEX at Liberec. http://doi.org/10.13140/2.1.3350.8161

[17] Yu, H. (2014). A cross-cultural analysis of symbolic meanings of colour. Chang Gung Journal of Humanities and Social Sciences. 7(1), 49-74.

[18] Zammitto, V. I. (2005). The expressions of colours. Proceedings of DiGRA 2005 Conference: Changing Views - Worlds in Play. 